\title{
Serum 25-hydroxyvitamin D and Metabolic Parameters in Healthy Korean Adults: Korean National Health and Nutrition Examination Survey VI
}

\author{
Jeonghoon $\mathrm{Ha} \mathbb{I D}^{\prime}$ \\ Hansang Baek (D) ${ }^{\prime}$ \\ Chaiho Jeong $\mathbb{D}^{2}$ \\ Hyunsam $\mathrm{Kim}^{3}$ \\ Ki-Hyun Baek (D) ${ }^{4}$ \\ Moo II Kang' \\ Dong-Jun Lim (1D)
}

'Division of Endocrinology and Metabolism, Department of Internal Medicine, Seoul St. Mary's Hospital, College of Medicine, The Catholic University of Korea, Seoul, Korea; ${ }^{2}$ Division of Endocrinology and Metabolism, Department of Internal Medicine, Uijeongbu St. Mary's Hospital, College of Medicine, The Catholic University of Korea, Uijeongbu, Korea;

${ }^{3}$ Department of Internal Medicine, Dongshin Hospital, Seoul, Korea; ${ }^{4}$ Division of Endocrinology and Metabolism, Department of Internal Medicine, Yeouido St. Mary's Hospital, College of Medicine, The Catholic University of Korea, Seoul, Korea

Correspondence: Dong-Jun Lim Division of Endocrinology and Metabolism, Department of Internal Medicine, Seoul St. Mary's Hospital, College of Medicine, The Catholic University of Korea, Seoul, Korea Email Idj6026@catholic.ac.kr
Purpose: Studies investigating the association between vitamin D and metabolic parameters have reported inconsistent results depending on the characteristics of the subjects. We aimed to investigate the association between vitamin D levels and various metabolic indicators in healthy Korean adults by using nationally representative data.

Methods: A total of 3640 participants were included after excluding subjects who were $\leq 19$ years of age and had a history of treatment for dyslipidemia, hypertension, or diabetes and a history of other chronic diseases such as liver and kidney diseases. After dividing the 25-hydroxyvitamin $\mathrm{D}(25(\mathrm{OH}) \mathrm{D})$ level into quartiles, the risk of having each metabolic parameter higher than the median value was determined according to the $25(\mathrm{OH}) \mathrm{D}$ quartile by using regression analysis.

Results: In a multivariate regression analysis, a higher $25(\mathrm{OH}) \mathrm{D}$ quartile tended to have a significantly lower risk of having a triglyceride (TG) level higher than the median value $(103.1 \mathrm{mg} / \mathrm{dl})$. As the quartile increased, the risk of having a waist circumference or body mass index higher than the median value also decreased, but the difference was not statistically significant. No significant changes were observed in fasting glucose or glycated hemoglobin level according to quartile.

Conclusion: We demonstrated that subjects with a higher $25(\mathrm{OH}) \mathrm{D}$ quartile exhibited a significantly lower risk of having a TG level higher than the median value in a representative Korean population. More evidence from a prospective study on whether vitamin D supplementation improves serum TG levels in healthy adults is needed.

Keywords: 25-hydroxyvitamin D, triglyceride, glucose, body mass index, waist circumference

\section{Introduction}

Vitamin D is involved in maintaining homeostasis of calcium and phosphorus and is an important substance involved in bone metabolism. ${ }^{1}$ Various studies have investigated the effects of vitamin D supplementation not only on skeletal effects, but also on non-skeletal effects, such as on the cardiovascular system, glucose metabolism, infectious diseases, diabetic complications, and cancers. ${ }^{2,3}$ Vitamin $\mathrm{D}$ receptors are expressed in a variety of body tissues and have different physiological effects. ${ }^{4}$ They are also located in pancreatic $\beta$-cells, and vitamin D is involved in insulin secretion and insulin sensitivity. ${ }^{5}$ Previous studies have shown that low blood vitamin D levels increase the risk of dysfunction in glucose metabolism. ${ }^{6,7}$

Pittas et al found that vitamin D supplementation lowers the risk of type 2 diabetes $^{8}$ whereas Seida et al reported no effect of vitamin D supplementation on 
glucose homeostasis or diabetes prevention. ${ }^{9}$ A study conducted on Korean subjects reported that vitamin D is associated with glucose metabolism, ${ }^{10}$ but this finding is inconsistent with other studies. ${ }^{11,12}$ These inconclusive results are due to the heterogeneity of the study subjects, the variable risk of bias, and the differences in the followup period. Therefore, limitations exist in drawing clear conclusions with regard to the association between vitamin $\mathrm{D}$ and glucose homeostasis.

Vitamin D deficiency, defined as a vitamin D concentration of less than $20 \mathrm{ng} / \mathrm{mL}$, is commonly observed in Korea, ${ }^{13}$ particularly in the younger generations. ${ }^{13}$ Studies in Korea confirmed the association between vitamin $\mathrm{D}$ concentration and glucose homeostasis in healthy adults. However, few of them reported the association between vitamin $\mathrm{D}$ concentration and various metabolic components constituting metabolic syndrome in healthy adults. Therefore, in this study, we aimed to investigate the association between vitamin $\mathrm{D}$ concentration, fasting blood glucose, glycated hemoglobin (HbA1c), triglyceride (TG), waist circumference (WC), and body mass index (BMI) in healthy adults by using nationally representative data from the Korea National Health and Nutrition Examination Survey (KNHANES).

\section{Materials and Methods}

\section{Study Population}

The KNHANES VI was performed by the Korea Centers for Disease Control and Prevention. It is composed of a health interview survey, a health examination survey, and a nutrition survey using a stratified, multistage, probability sampling design. Written informed consent for participation was obtained from all study subjects. Detailed information regarding data collection is available on the KNHANES website (https://knhanescdcgokr/knhanes/ indexdo). The data accessed from the KNHANES is freely available upon request. The study was approved by the Catholic University of Korea, Catholic Medical Center, Seoul St. Mary's Hospital Institutional Review Board. Among the 4117 Korean participants aged $>19$ years, 370 were excluded from the study because of a history of treatment for dyslipidemia, hypertension, or diabetes. Eighty-two subjects receiving vitamin D supplementation and 25 subjects with chronic diseases, such as liver or kidney disease, were also excluded. Finally, 3640 participants were included in the analysis.

\section{Measurements}

All measurements and questionnaires were collected by trained investigators. Detailed anthropometric measurements were performed according to our previous studies. ${ }^{14-16}$ Height and body weight were measured as part of the health examination for each subject. BMI was calculated from the measured height and weight values. Serum vitamin D levels (25-hydroxyvitamin D, 25(OH)D) were measured using a gamma counter (1470 WIZARD gamma-counter; PerkinElmer, Turku, Finland) with a radioimmunoassay assay (DiaSorin, Stillwater, MN, USA). Vitamin D deficiency is defined as a $25(\mathrm{OH}) \mathrm{D}$ concentration of less than $20 \mathrm{ng} / \mathrm{mL} .{ }^{4} 25(\mathrm{OH}) \mathrm{D}$ concentration was analyzed by dividing the population into quartiles. Serum glucose, $\mathrm{HbAlc}$, and TG levels were measured from blood samples collected after $8 \mathrm{~h}$ of overnight fasting. Fasting plasma glucose levels were determined with the Hitachi 7600 automatic analyzer (Hitachi, Tokyo, Japan). HbAlc levels were measured using high-performance liquid chromatography (HLC723G7; Tosoh, Tokyo, Japan). The smoking status of the subjects was classified as either non-smokers or current smokers. Physical activity was categorized into regular physical activity (exercise session for $\geq 20 \mathrm{~min} / \mathrm{session}, \geq 5$ sessions/week; moderate exercise for $\geq 30 \mathrm{~min} / \mathrm{session}, \geq 5$ sessions/week; or walking for $\geq 30 \mathrm{~min} / \mathrm{session}, \geq 5$ sessions/week) and non-regular physical activity groups.

\section{Statistical Analysis}

Statistical analyses were performed using SAS version 9.3 (SAS Institute, Cary, NC, USA). Statistical significance was set at $\mathrm{P}<0.05$. Continuous variables are expressed as numbers and percentages or as means \pm standard deviations and were compared using t-tests. Discrete variables are presented as $\mathrm{N}(\%)$ and compared using the Rao-Scott chi-squared test. Analysis of variance was performed to analyze the difference between the $25(\mathrm{OH}) \mathrm{D}$ quartiles. Multivariable adjusted logistic regression analysis was performed to determine odds ratios (ORs) and 95\% confidence intervals (CIs). In the logistic regression analysis, Model 1 was an unadjusted model (crude), whereas Model 2 was adjusted for age and sex. Model 3 was fully adjusted for age, sex, physical activity, smoking status, and blood pressure. Because of the complex sampling design, a sampling weight method was used to assign the participants as representatives of the Korean population for data analysis. The statistical analysis of KNHANES has been reported in previous studies. ${ }^{15,17-20}$ 
Table I Baseline Characteristics of Study Participants

\begin{tabular}{|c|c|c|c|c|c|}
\hline & \multicolumn{4}{|c|}{ 25-Hydroxyvitamin D Quartiles } & \multirow[t]{2}{*}{$P$ value } \\
\hline & $Q \mid(n=865)$ & Q $2(n=899)$ & Q $3(n=891)$ & Q $4(n=985)$ & \\
\hline Age (years) & $36.3 \pm 0.5$ & $38.1 \pm 0.5$ & $40.0 \pm 0.6$ & $44.6 \pm 0.5$ & $<0.001$ \\
\hline Female, n (\%) & $527(5 । .5)$ & $500(46.5)$ & $4 I I(38.1)$ & $416(34.8)$ & $<0.001$ \\
\hline Fasting glucose $(\mathrm{mg} / \mathrm{dL})$ & $93.3 \pm 0.4$ & $95.3 \pm 0.7$ & $95.7 \pm 0.5$ & $96.9 \pm 0.7$ & $<0.001$ \\
\hline HbAlc (\%) & $5.5 \pm 0.01$ & $5.6 \pm 0.02$ & $5.6 \pm 0.01$ & $5.7 \pm 0.02$ & $<0.001$ \\
\hline Triglyceride (mg/dL) & $140.2 \pm 5.2$ & $|3| .4 \pm 4.5$ & $139.8 \pm 4.5$ & $140.2 \pm 4.1$ & 0.416 \\
\hline $\mathrm{HDL}(\mathrm{mg} / \mathrm{dL})$ & $50.8 \pm 0.5$ & $52.3 \pm 0.4$ & $51.4 \pm 0.4$ & $50.3 \pm 0.4$ & 0.096 \\
\hline BMI $\left(\mathrm{kg} / \mathrm{m}^{2}\right)$ & $23.5 \pm 0.1$ & $23.4 \pm 0.1$ & $23.8 \pm 0.1$ & $23.8 \pm 0.1$ & 0.059 \\
\hline Mean 25 -Hydroxyvitamin $D(\mathrm{ng} / \mathrm{mL})$ & $9.49 \pm 0.06$ & $13.62 \pm 0.03$ & $17.33 \pm 0.04$ & $25.12 \pm 0.16$ & $<0.001$ \\
\hline Waist circumference $(\mathrm{cm})$ & $79.2 \pm 0.4$ & $79.4 \pm 0.4$ & $80.8 \pm 0.4$ & $81.1 \pm 0.4$ & 0.001 \\
\hline Systolic pressure (mmHg) & $113.1 \pm 0.5$ & $113.4 \pm 0.5$ & $115.1 \pm 0.6$ & $116.4 \pm 0.6$ & $<0.001$ \\
\hline Diastolic pressure $(\mathrm{mmHg})$ & $74.6 \pm 0.4$ & $74.9 \pm 0.4$ & $75.3 \pm 0.4$ & $76.4 \pm 0.4$ & 0.010 \\
\hline $\begin{array}{c}\text { Physical activity } \\
\text { Yes, n (\%) }\end{array}$ & $424(56.3)$ & $44 \mid(57.3)$ & $436(56.4)$ & $489(57.8)$ & 0.929 \\
\hline $\begin{array}{l}\text { Smoking } \\
\text { Yes, n (\%) }\end{array}$ & $306(42.8)$ & $337(45.6)$ & $388(5 \mathrm{I} . \mathrm{I})$ & 431 (49.3) & 0.015 \\
\hline
\end{tabular}

Notes: QI: $\leq$ II $.87 \mathrm{ng} / \mathrm{mL}, \quad$ I $1.87 \mathrm{ng} / \mathrm{mL}<\mathrm{Q} 2 \leq 15.33 \mathrm{ng} / \mathrm{mL}, 15.33 \mathrm{ng} / \mathrm{mL}<\mathrm{Q} 3 \leq 19.65 \mathrm{ng} / \mathrm{mL}$, and $19.65 \mathrm{ng} / \mathrm{mL}<\mathrm{Q} 4$. Data are presented as mean \pm se, $\mathrm{n}$ (weighted \%); Statistics were carried out using Rao-Scott Chi-square test and $t$-test.

Abbreviation: BMI, Body mass index.

\section{Results}

\section{Baseline Characteristics According to the 25(OH)D Quartiles}

The differences in baseline characteristics according to the 25(OH)D quartile are presented in Table 1. 25(OH)D quartiles $(\mathrm{Q})$ were classified as follows: $\mathrm{Q} 1: \leq 11.87 \mathrm{ng} /$ $\mathrm{mL}, 11.87 \mathrm{ng} / \mathrm{mL}<\mathrm{Q} 2 \leq 15.33 \mathrm{ng} / \mathrm{mL}, 15.33 \mathrm{ng} / \mathrm{mL}<\mathrm{Q} 3$ $\leq 19.65 \mathrm{ng} / \mathrm{mL}$, and $19.65 \mathrm{ng} / \mathrm{mL}<\mathrm{Q} 4$. The mean age in Q4 was the highest (44.6 \pm 0.5 years), whereas that in Q1 was the lowest $(36.3 \pm 0.5$ years $)(p<0.001)$. The higher the quartile, the fewer female participants were included $(\mathrm{p}$ $<0.001$ ). Fasting glucose, HbA1c, systolic blood pressure, diastolic blood pressure, and WC tended to increase with increasing quartile. BMI and serum TG levels did not differ between the quartiles.

\section{Association of 25(OH)D with Metabolic Parameters}

In the study population, the median values for fasting glucose, HbA1c, TG, high-density lipoprotein (HDL) cholesterol, WC, and BMI were $91.9 \mathrm{mg} / \mathrm{dl}, 5.5 \%$, $103.1 \mathrm{mg} / \mathrm{dl}, 49.5 \mathrm{mg} / \mathrm{dl}, 79.6 \mathrm{~cm}$, and $23.3 \mathrm{~kg} / \mathrm{m}^{2}$, respectively (Tables 2-7). In multiple regression analyses, the risk of having a fasting glucose level higher than the median value $(91.9 \mathrm{mg} / \mathrm{dl})$ increased in the crude model (Model 1) with an increase in the $25(\mathrm{OH}) \mathrm{D}$ quartile (Table 2). However, no statistical difference was found in this trend in Model 3, which is a fully adjusted model (OR: $0.977,95 \%$ CI, 0.754-1.385, $\mathrm{p}=0.255$; Table 2). The risk of having an HbAlc level higher than the median value $(5.5 \%)$ increased in the crude model with an increase in 25 (OH)D quartile. However, these changes were not statistically significant in Model 3 (OR: 1.117, 95\% CI, 0.9111.524, $\mathrm{p}=0.190$; Table 3). In the fully adjusted Model 3, a higher 25(OH)D quartile was confirmed to lower the risk of having a TG level higher than the median value $(103.1 \mathrm{mg} / \mathrm{dl})$. In subjects in the highest quartile (Q4), the risk of having a TG level higher than $103.1 \mathrm{mg} / \mathrm{dl}$ was $22.4 \%$ lower (OR: $0.776,95 \%$ CI, 0.603-0.999, p = 0.005 ) than that in $\mathrm{Q} 1$ subjects in Model 3 ( $\mathrm{p}$ for trend = 0.032; Table 4). The risk of having HDL cholesterol, WC, 
Table 2 Multiple Logistic Regression of Metabolic Parameters According to 25(OH)D Quartile Fasting Glucose

\begin{tabular}{|c|c|c|c|}
\hline \multirow[t]{2}{*}{$\begin{array}{l}25(\mathrm{OH}) \mathrm{D} \\
\text { quartiles }\end{array}$} & \multicolumn{2}{|c|}{$\begin{array}{l}\text { Fasting Glucose (> Median } \\
(91.9 \mathrm{mg} / \mathrm{dl}))\end{array}$} & \multirow[t]{2}{*}{$\begin{array}{l}\text { OR for } \\
\text { trend }\end{array}$} \\
\hline & OR $(95 \% \mathrm{Cl})$ & $p$ value & \\
\hline Model I (Crude) & & & 0.003 \\
\hline Q I & Reference & & \\
\hline Q 2 & $1.280(1.034-1.586)$ & 0.023 & \\
\hline Q 3 & $1.388(1.100-1.752)$ & 0.006 & \\
\hline Q 4 & $1.403(1.132-1.740)$ & 0.002 & \\
\hline Model 2 & & & 0.206 \\
\hline Q I & Reference & & \\
\hline Q 2 & I.I 64 (0.923-I.469) & 0.199 & \\
\hline Q 3 & I.I08 (0.865-I.419) & 0.417 & \\
\hline Q 4 & $0.856(0.677-\mid .08 I)$ & 0.191 & \\
\hline Model 3 & & & 0.176 \\
\hline Q I & Reference & & \\
\hline Q 2 & I.I47 (0.80I-I.990) & 0.193 & \\
\hline Q 3 & $0.925(0.967-1.438)$ & 0.205 & \\
\hline Q 4 & $0.977(0.754-1.385)$ & 0.255 & \\
\hline
\end{tabular}

Notes: $25(\mathrm{OH}) \mathrm{D}$ quartiles are classified as $\mathrm{Q} 1: \leq 11.87 \mathrm{ng} / \mathrm{mL}, 11.87 \mathrm{ng} / \mathrm{mL}<\mathrm{Q} 2 \leq 15.33$ $\mathrm{ng} / \mathrm{mL}$, $15.33 \mathrm{ng} / \mathrm{mL}<\mathrm{Q} 3 \leq 19.65 \mathrm{ng} / \mathrm{mL}$, and $19.65 \mathrm{ng} / \mathrm{mL}<\mathrm{Q} 4$; Model I was unadjusted model, whereas Model 2 was the model that was adjusted by age, sex. Model 3 was a fullyadjusted by age, sex, physical activity, smoking status, and blood pressure.

Abbreviation: 25(OH)D, 25-hydroxyvitamin $\mathrm{D}$.

Table 3 Multiple Logistic Regression of Metabolic Parameters According to 25(OH)D Quartile HbAlc

\begin{tabular}{|c|c|c|c|}
\hline \multirow{2}{*}{$\begin{array}{l}25(\mathrm{OH}) \mathrm{D} \\
\text { quartiles }\end{array}$} & \multicolumn{2}{|c|}{ HbAlc (> Median (5.5\%)) } & \multirow{2}{*}{$\begin{array}{l}\text { OR for } \\
\text { trend }\end{array}$} \\
\hline & OR $(95 \% \mathrm{CI})$ & $p$ value & \\
\hline Model I (Crude) & & & $<0.001$ \\
\hline Q I & Reference & & \\
\hline Q 2 & $1.156(0.933-1.434)$ & 0.185 & \\
\hline Q 3 & $1.309(1.042-1.644)$ & 0.021 & \\
\hline Q 4 & $1.832(1.449-2.316)$ & $<0.001$ & \\
\hline Model 2 & & & 0.251 \\
\hline Q I & Reference & & \\
\hline Q 2 & $\mathrm{I} .040(0.827-\mathrm{I} .307)$ & 0.738 & \\
\hline Q 3 & $\mathrm{I} .057(0.83 \mathrm{I}-\mathrm{I} .345)$ & 0.649 & \\
\hline Q 4 & I.I $67(0.903-1.509)$ & 0.237 & \\
\hline Model 3 & & & 0.175 \\
\hline Q I & Reference & & \\
\hline Q 2 & $1.210(0.657-2.225)$ & 0.540 & \\
\hline Q 3 & $0.815(0.733-1.333)$ & 0.300 & \\
\hline Q 4 & $1.117(0.911-1.524)$ & 0.190 & \\
\hline
\end{tabular}

Notes: $25(\mathrm{OH}) \mathrm{D}$ quartiles are classified as $\mathrm{Q} \mathrm{I}: \leq 11.87 \mathrm{ng} / \mathrm{mL}, 11.87 \mathrm{ng} / \mathrm{mL}<\mathrm{Q} 2$ $\leq 15.33 \mathrm{ng} / \mathrm{mL}, 15.33 \mathrm{ng} / \mathrm{mL}<\mathrm{Q} 3 \leq 19.65 \mathrm{ng} / \mathrm{mL}$, and $19.65 \mathrm{ng} / \mathrm{mL}<\mathrm{Q} 4$; Model I was unadjusted model, whereas Model 2 was the model that was adjusted by age, sex. Model 3 was a fully-adjusted by age, sex, physical activity, smoking status, and blood pressure.

Abbreviation: 25(OH)D, 25-hydroxyvitamin D.
Table 4 Multiple Logistic Regression of Metabolic Parameters According to 25(OH)D Quartile Triglyceride

\begin{tabular}{|c|c|c|c|}
\hline \multirow[t]{2}{*}{$\begin{array}{l}\mathbf{2 5}(\mathrm{OH}) \mathrm{D} \\
\text { quartiles }\end{array}$} & \multicolumn{2}{|c|}{$\begin{array}{l}\text { Triglyceride (> Median } \\
((103.1 \mathrm{mg} / \mathrm{dl}))\end{array}$} & \multirow[t]{2}{*}{$\begin{array}{l}\text { OR for } \\
\text { trend }\end{array}$} \\
\hline & OR (95\% CI) & $p$ value & \\
\hline Model I (Crude) & & & 0.004 \\
\hline Q I & Reference & & \\
\hline Q 2 & $0.962(0.784-1.179)$ & 0.706 & \\
\hline Q 3 & $1.160(0.940-1.430)$ & 0.165 & \\
\hline Q 4 & $1.307(1.052-1.625)$ & 0.016 & \\
\hline Model 2 & & & 0.198 \\
\hline Q I & Reference & & \\
\hline Q 2 & $0.850(0.687-1.05 I)$ & 0.134 & \\
\hline Q 3 & $0.982(0.720-1.105)$ & 0.293 & \\
\hline Q 4 & $0.840(0.666-1.06 \mathrm{I})$ & 0.143 & \\
\hline Model 3 & & & $0.032 *$ \\
\hline Q I & Reference & & \\
\hline Q 2 & $0.835(0.659-1.059)$ & 0.137 & \\
\hline Q 3 & $0.752(0.595-0.95 I)$ & 0.018 & \\
\hline Q 4 & $0.776(0.603-0.999)$ & 0.005 & \\
\hline
\end{tabular}

Notes: $25(\mathrm{OH}) \mathrm{D}$ quartiles are classified as $\mathrm{QI}: \leq 11.87 \mathrm{ng} / \mathrm{mL}, 11.87 \mathrm{ng} / \mathrm{mL}<\mathrm{Q} 2$ $\leq 15.33 \mathrm{ng} / \mathrm{mL}, 15.33 \mathrm{ng} / \mathrm{mL}<\mathrm{Q} 3 \leq 19.65 \mathrm{ng} / \mathrm{mL}$, and $19.65 \mathrm{ng} / \mathrm{mL}<\mathrm{Q} 4$; Model I was unadjusted model, whereas Model 2 was the model that was adjusted by age, sex. Model 3 was a fully-adjusted by age, sex, physical activity, smoking status, and blood pressure; *For the significant results.

Abbreviation: 25(OH)D, 25-hydroxyvitamin D.

Table 5 Multiple Logistic Regression of Metabolic Parameters According to 25(OH)D Quartile HDL-Cholesterol

\begin{tabular}{|c|c|c|c|}
\hline \multirow[t]{2}{*}{$\begin{array}{l}\text { 25(OH)D } \\
\text { quartiles }\end{array}$} & \multicolumn{2}{|c|}{$\begin{array}{l}\text { HDL-Cholesterol (> Median } \\
\text { (49.5 mg/dl)) }\end{array}$} & \multirow[t]{2}{*}{$\begin{array}{l}\text { OR for } \\
\text { trend }\end{array}$} \\
\hline & OR (95\% Cl) & $p$ value & \\
\hline Model I (Crude) & & & 0.664 \\
\hline Q I & Reference & & \\
\hline Q 2 & $\mathrm{I} .194(0.964-\mathrm{I} .480)$ & 0.105 & \\
\hline Q 3 & I.I38 (0.922-I.404) & 0.229 & \\
\hline Q 4 & $0.968(0.788-1.190)$ & 0.760 & \\
\hline Model 2 & & & 0.105 \\
\hline Q I & Reference & & \\
\hline Q 2 & 1.327 (0.96I-I.359) & 0.113 & \\
\hline Q 3 & $1.433(0.854-1.484)$ & 0.301 & \\
\hline Q 4 & $1.376(0.900-1.522)$ & 0.225 & \\
\hline Model 3 & & & 0.331 \\
\hline Q I & Reference & & \\
\hline Q 2 & $0.734(0.372-1.450)$ & 0.373 & \\
\hline Q 3 & $1.347(0.656-2.767)$ & 0.416 & \\
\hline Q 4 & $1.230(0.617-2.452)$ & 0.555 & \\
\hline
\end{tabular}

Notes: $25(\mathrm{OH}) \mathrm{D}$ quartiles are classified as $\mathrm{Q} \mathrm{I}: \leq 11.87 \mathrm{ng} / \mathrm{mL}, 11.87 \mathrm{ng} / \mathrm{mL}<\mathrm{Q} 2 \leq 15.33$ $\mathrm{ng} / \mathrm{mL}$, $15.33 \mathrm{ng} / \mathrm{mL}<\mathrm{Q} 3 \leq 19.65 \mathrm{ng} / \mathrm{mL}$, and $19.65 \mathrm{ng} / \mathrm{mL}<\mathrm{Q} 4$; Model I was unadjusted model, whereas Model 2 was the model that was adjusted by age, sex. Model 3 was a fullyadjusted by age, sex, physical activity, smoking status, and blood pressure. Abbreviation: 25(OH)D, 25-hydroxyvitamin D. 
Table 6 Multiple Logistic Regression of Metabolic Parameters According to 25(OH)D Quartile Waist Circumference

\begin{tabular}{|c|c|c|c|}
\hline \multirow[t]{2}{*}{$\begin{array}{l}25(\mathrm{OH}) \mathrm{D} \\
\text { quartiles }\end{array}$} & \multicolumn{2}{|c|}{$\begin{array}{l}\text { Waist Circumference (> } \\
\text { Median }(79.6 \mathrm{~cm}))\end{array}$} & \multirow[t]{2}{*}{$\begin{array}{l}\text { OR for } \\
\text { trend }\end{array}$} \\
\hline & OR (95\% Cl) & $p$ value & \\
\hline Model I (Crude) & & & $<0.001$ \\
\hline Q I & Reference & & \\
\hline Q 2 & $1.035(0.705-1.170)$ & 0.761 & \\
\hline Q 3 & $\mathrm{I} .080(0.84 \mathrm{I}-\mathrm{I} .387)$ & 0.004 & \\
\hline Q 4 & $0.977(0.759-1.258)$ & $<0.001$ & \\
\hline Model 2 & & & 0.795 \\
\hline Q I & Reference & & \\
\hline Q 2 & $0.909(0.705-1.170)$ & 0.457 & \\
\hline Q 3 & $1.080(0.84 I-1.387)$ & 0.546 & \\
\hline Q 4 & $0.977(0.759-1.258)$ & 0.858 & \\
\hline Model 3 & & & 0.319 \\
\hline Q I & Reference & & \\
\hline Q 2 & $0.865(0.400-1.799)$ & 0.666 & \\
\hline Q 3 & $0.843(0.4 \mid 3-1.814)$ & 0.701 & \\
\hline Q 4 & $0.783(0.735-2.410)$ & 0.240 & \\
\hline
\end{tabular}

Notes: $25(\mathrm{OH}) \mathrm{D}$ quartiles are classified as $\mathrm{Q} 1: \leq 1 \mathrm{I} .87 \mathrm{ng} / \mathrm{mL}, 1 \mathrm{I} .87 \mathrm{ng} / \mathrm{mL}<\mathrm{Q} 2 \leq 15.33$ $\mathrm{ng} / \mathrm{mL}, 15.33 \mathrm{ng} / \mathrm{mL}<\mathrm{Q} 3 \leq 19.65 \mathrm{ng} / \mathrm{mL}$, and $19.65 \mathrm{ng} / \mathrm{mL}<\mathrm{Q} 4$; Model I was unadjusted model, whereas Model 2 was the model that was adjusted by age, sex. Model 3 was a fullyadjusted by age, sex, physical activity, smoking status, and blood pressure.

Abbreviation: 25(OH)D, 25-hydroxyvitamin D.

Table 7 Multiple Logistic Regression of Metabolic Parameters According to 25(OH)D Quartile Body Mass Index

\begin{tabular}{|c|c|c|c|}
\hline \multirow[t]{2}{*}{$\begin{array}{l}\text { 25(OH)D } \\
\text { quartiles }\end{array}$} & \multicolumn{2}{|c|}{$\begin{array}{c}\text { Body Mass Index (> Median } \\
\left.\left(23.3 \mathrm{~kg} / \mathrm{m}^{2}\right)\right)\end{array}$} & \multirow[t]{2}{*}{$\begin{array}{l}\text { OR for } \\
\text { trend }\end{array}$} \\
\hline & OR (95\% Cl) & $p$ value & \\
\hline Model I (Crude) & & & 0.003 \\
\hline Q I & Reference & & \\
\hline Q 2 & $1.032(0.827-1.288)$ & 0.779 & \\
\hline Q 3 & 1.271 (I.007-I.602) & 0.043 & \\
\hline Q 4 & $1.336(1.069-1.670)$ & 0.011 & \\
\hline Model 2 & & & 0.914 \\
\hline Q I & Reference & & \\
\hline Q 2 & $0.950(0.753-1.198)$ & 0.665 & \\
\hline Q 3 & $1.060(0.83 \mathrm{I}-\mathrm{I} .350)$ & 0.639 & \\
\hline Q 4 & $0.977(0.773-1.234)$ & 0.844 & \\
\hline Model 3 & & & 0.426 \\
\hline Q I & Reference & & \\
\hline Q 2 & 1.031 (0.519-2.048) & 0.931 & \\
\hline Q 3 & $0.984(0.482-2.006)$ & 0.964 & \\
\hline Q 4 & $0.75 \mid(0.382-1.478)$ & 0.407 & \\
\hline
\end{tabular}

Notes: $25(\mathrm{OH}) \mathrm{D}$ quartiles are classified as $\mathrm{Q}|: \leq 1 \mathrm{I} .87 \mathrm{ng} / \mathrm{mL}, \mathrm{I}| .87 \mathrm{ng} / \mathrm{mL}<\mathrm{Q} 2 \leq 15.33$ $\mathrm{ng} / \mathrm{mL}, 15.33 \mathrm{ng} / \mathrm{mL}<\mathrm{Q} 3 \leq 19.65 \mathrm{ng} / \mathrm{mL}$, and $19.65 \mathrm{ng} / \mathrm{mL}<\mathrm{Q} 4$; Model I was unadjusted model, whereas Model 2 was the model that was adjusted by age, sex. Model 3 was a fullyadjusted by age, sex, physical activity, smoking status, and blood pressure. Abbreviation: 25(OH)D, 25-hydroxyvitamin D. and BMI higher than the median value decreased as the quartile of 25(OH)D increased in Model 3, but the difference was not statistically significant (Tables 5-7).

\section{Discussion}

This population-based study analyzed the association between various metabolic parameters and vitamin D concentration in 3640 healthy adults aged $>19$ years. In a fully adjusted model, the risk of having TG level, WC, and BMI higher than the average value decreased as the 25 $(\mathrm{OH}) \mathrm{D}$ concentration increased. The changes in the TG level were statistically significant.

Numerous studies have investigated the association between vitamin $\mathrm{D}$ levels and metabolic parameters. Alvarez and Ashraf reported a negative correlation between vitamin $\mathrm{D}$ concentrations and fasting blood glucose levels. ${ }^{21}$ McGill et al found that HbAlc level decreases as the concentration of vitamin $\mathrm{D}$ increases in overweight or obese subjects. ${ }^{22}$ Many studies have shown that the concentration of vitamin D has a negative correlation with fasting blood glucose and $\mathrm{HbAlc}$; however, some studies reported opposite findings. A study on Jordanian adults aged 18 years or older reported no association between serum 25(OH)D levels and factors constituting metabolic syndrome, including fasting blood glucose. $^{23}$ A study analyzing 292 postmenopausal women aged 50-79 years included in the Women's Health Initiative Calcium-Vitamin D (WHI-CaD) trial also reported no association between $25(\mathrm{OH}) \mathrm{D}$ concentration and glucose or insulin. However, in our study, high 25 (OH)D concentration was inversely associated with TG. ${ }^{11}$ In a study involving 813 Korean adults (324 men and 483 women) residing in a rural area, univariate analysis showed that $25(\mathrm{OH}) \mathrm{D}$ and insulin resistance are inversely associated, but this association is not significant after adjusting for several variables. ${ }^{12}$ Studies investigating the association between $25(\mathrm{OH}) \mathrm{D}$ concentration and insulin resistance, diabetes, and fasting blood glucose showed inconsistent results depending on the characteristics of the analyzed group. Most studies investigated about the association between 25(OH)D and fasting blood glucose and insulin resistance. Studies confirming the association between 25(OH)D and metabolic syndrome components in a single study group are lacking. In this study, we included 3640 healthy Korean adult men and women and analyzed the association between $25(\mathrm{OH}) \mathrm{D}$ and various components such as fasting blood glucose, HbA1c, TG, WC, and BMI. Multivariate analysis showed that a higher 25(OH)D 
quartile tended to have a lower risk of TG level higher than the median value. Although no statistical difference was found, it was confirmed that the higher the $25(\mathrm{OH}) \mathrm{D}$ concentration, the lower the risk of having $\mathrm{WC}$ and $\mathrm{BMI}$ higher than the average value. This finding is in line with the results of the WHI-CaD trial. Studies on the association between vitamin $\mathrm{D}$ and lipids, including TG, have been conducted. Chunla et al reported an inverse correlation between serum 25(OH)D and TG levels in a metaanalysis of patients with polycystic ovary syndrome (PCOS) ${ }^{24}$ Asemi et al showed that calcium and vitamin D supplementation have beneficial effects on serum TG levels in patients with PCOS. ${ }^{25}$ However, the beneficial effects of vitamin D supplementation on TGs are negative according to the current evidence. Rajpathak et al found that calcium and vitamin D supplementation in postmenopausal women is not associated with lipid changes over five years. ${ }^{26}$ In a study of 39 healthy postmenopausal women, elemental calcium $(1000 \mathrm{mg} /$ day $)$ and vitamin D supplementation (800 IU/day) are not associated with significant changes in lipid levels over 3 months. ${ }^{27}$ These inconsistent results may be due to the differences in the study subjects and study duration. Further studies on subjects with different characteristics are required. Our study analyzed healthy adults, and confirming the association between vitamin D and TG levels in healthy adults is important. In our study, although the risk of having a TG level higher than the median value was significantly lower when the serum $25(\mathrm{OH}) \mathrm{D}$ quartile was increased in healthy adults, whether supplementation of vitamin D has an effect on reducing TG levels is uncertain. The effect of vitamin $\mathrm{D}$ on serum TG levels remains unknown. However, several possible mechanisms have been identified on how serum vitamin D affects TG levels. Querfeld et al suggested that upregulated lipoprotein lipase induced by vitamin D metabolites can reduce the formation of TGs and induce the formation of HDL cholesterol in vitro. ${ }^{28}$ Moreover, the anti-inflammatory effect of vitamin D might reduce chronic inflammation, thus lowering TG levels. ${ }^{29,30}$ In our study, an increase in the $25(\mathrm{OH}) \mathrm{D}$ quartile was confirmed to have a beneficial effect on TG and HDL cholesterol levels. More research is warranted on the effects of vitamin D on lipid metabolism.

These results were also observed for the other metabolic parameters. Recently, many studies have observed changes in insulin resistance or fasting blood glucose when vitamin D was supplemented, but a meta-analysis failed to prove the usefulness of vitamin D supplementation. ${ }^{2}$ As such, the association between vitamin $\mathrm{D}$ and metabolic parameters as well as the usefulness of vitamin D supplementation for metabolic diseases have not been clearly demonstrated because of the different demographic characteristics of the study subjects, and type 1 error or attrition bias may affect the interpretation of the study results.

This study has several limitations. First, as this study has a cross-sectional design, explanation of the causal association between serum 25(OH)D concentration and metabolic parameters is limited. Second, changes in vitamin D due to differences in sunlight exposure or seasonal differences were not considered in the analysis. Third, this study did not determine the intake of vitamin D from dietary sources, which usually contain cholesterol. As such, their effects should be considered. Fourth, the subjects included smokers, but smokers may have metabolic problems, such as obesity, and vitamin D binding protein may be low; therefore, caution is needed in interpreting the vitamin D levels. ${ }^{31,32}$ Finally, information on drug use, detailed history of treatment, and presence of medical conditions were collected based on self-reports. However, the KNHANES provides reliable data because a specially trained investigator participated in the interview, and many studies have been conducted based on these data. Nevertheless, the important clinical implications of our study should not be overlooked. The KNHANES is a nationally representative sample of the Korean population. The present study has the advantage of investigating healthy adults without diabetes or other metabolic diseases.

\section{Conclusion}

To our knowledge, this study is the largest to investigate the association between $25(\mathrm{OH}) \mathrm{D}$ and metabolic parameters in a Korean population. We demonstrated that subjects with a higher 25(OH)D quartile exhibited a significantly lower risk of having a TG level higher than the median value. By contrast, other parameters constituting metabolic syndrome and glucose homeostasis, such as fasting glucose, HbAlc, WC, and BMI, were not significantly associated with $25(\mathrm{OH}) \mathrm{D}$ quartiles. A prospective cohort study that complements the abovementioned limitations is expected to provide a broad understanding of the association between vitamin $\mathrm{D}$ and important metabolic parameters. In addition, evidence from a prospective study on whether vitamin D supplementation improves TG levels in healthy adults is needed. 


\section{Acknowledgments}

The statistical consultation was supported by a grant from the Korea Health Technology R\&D Project through the Korea Health Industry Development Institute, funded by the Ministry of Health \& Welfare, Republic of Korea (grant number: HI14C1062).

\section{Disclosure}

The authors declare that there is no conflict of interest regarding the publication of this paper.

\section{References}

1. Reid IR, Bolland MJ, Grey A. Effects of vitamin D supplements on bone mineral density: a systematic review and meta-analysis. Lancet. 2014;383(9912):146-55. doi:10.1016/S0140-6736(13)61647-5

2. Autier P, Mullie $P$, Macacu A, et al. Effect of vitamin D supplementation on non-skeletal disorders: a systematic review of meta-analyses and randomised trials. Lancet Diabetes Endocrinol. 2017;5(12):986-1004. doi:10.1016/S2213-8587(17)30357-1

3. Hong SH, Kim YB, Choi HS, et al. Association of Vitamin D deficiency with diabetic nephropathy. Endocrinol Metab (Seoul). 2021;36(1):106-113. doi:10.3803/EnM.2020.826

4. Thacher TD, Clarke BL. Vitamin D insufficiency. Mayo Clin Proc. 2011;86(1):50-60. doi:10.4065/mcp.2010.0567

5. Grammatiki M, Rapti E, Karras S, et al. Vitamin D and diabetes mellitus: causal or casual association? Rev Endocr Metab Disord. 2017;18(2):227-241. doi:10.1007/s11154-016-9403-y

6. Reis JP, von Muhlen D, Miller ER, et al. Vitamin D status and cardiometabolic risk factors in the United States adolescent population. Pediatrics. 2009;124(3):e371-9. doi:10.1542/peds.20090213

7. Pittas AG, Nelson J, Mitri J, et al. Plasma 25-hydroxyvitamin D and progression to diabetes in patients at risk for diabetes: an ancillary analysis in the diabetes prevention program. Diabetes Care. 2012;35 (3):565-73. doi: $10.2337 / \mathrm{dc} 11-1795$

8. Pittas AG, Dawson-Hughes B, Li T, et al. Vitamin D and calcium intake in relation to type 2 diabetes in women. Diabetes Care 2006;29(3):650-6. doi:10.2337/diacare.29.03.06.dc05-1961

9. Seida JC, Mitri J, Colmers IN, et al. Effect of Vitamin D 3 supplementation on improving glucose homeostasis and preventing diabetes: a systematic review and meta-analysis. $J$ Clin Endocrinol Metab. 2014;99(10):3551-60. doi:10.1210/jc.2014-2136

10. Lim S, Kim MJ, Lim S, et al. Association of vitamin D deficiency with incidence of type 2 diabetes in high-risk Asian subjects. Am J Clin Nutr. 2013;97(3):524-30. doi:10.3945/ajen.112.048496

11. Chacko SA, Song Y, Manson JE, et al. Serum 25-hydroxyvitamin $\mathrm{D}$ concentrations in relation to cardiometabolic risk factors and metabolic syndrome in postmenopausal women. Am J Clin Nutr. 2011;94(1):209-17. doi:10.3945/ajcn.110.010272

12. Song BM, Kim HC, Choi DP, et al. Association between serum 25-hydroxyvitamin $\mathrm{D}$ level and insulin resistance in a rural population. Yonsei Med J. 2014;55(4):1036-41. doi:10.3349/ ymj.2014.55.4.1036

13. Choi HS, Oh HJ, Choi H, et al. Vitamin D insufficiency in Korea-a greater threat to younger generation: the Korea National Health and Nutrition Examination Survey (KNHANES) 2008. J Clin Endocrinol Metab. 2011;96(3):643-51. doi:10.1210/jc.2010-2133

14. Ha J. Parathyroid hormone and vitamin D are associated with the risk of metabolic obesity in a middle-aged and older Korean population with preserved renal function: a cross-sectional study. PLoS One. 2017;12(4):e0175132. doi:10.1371/journal.pone.0175132
15. Ha J, Lee J, Lim D-J, et al. Association of serum free thyroxine and glucose homeostasis: Korea national health and nutrition examination survey. Korean $J$ Intern Med. 2021;36(Suppl 1):S170-s179. doi: $10.3904 / \mathrm{kjim} .2019 .160$

16. Ha J, Lee J, Jo K, et al. Sex differences in risk factors for subclinical hypothyroidism. Endocr Connect. 2018;7(4):511-522. doi:10.1530/ EC-18-0023

17. Kim J. Association between serum vitamin D, parathyroid hormone and metabolic syndrome in middle-aged and older Korean adults. Eur J Clin Nutr. 2015;69(4):425-30. doi:10.1038/ejcn.2014.192

18. Lee J, Ha J, Jo K, et al. Male-specific association between subclinical hypothyroidism and the risk of non-alcoholic fatty liver disease estimated by hepatic steatosis index: Korea national health and nutrition examination survey 2013 to 2015. Sci Rep. 2018;8(1):15145. doi:10.1038/s41598-018-32245-0

19. Kim W, Lee J, Ha J, et al. Association between sleep duration and subclinical thyroid dysfunction based on nationally representative data. J Clin Med. 2019;8(11):2010. doi:10.3390/jcm8112010

20. Lee J, Jo K, Ha J, et al. A significant association of upper limb muscle strength with thyroid function in overweight and obese population: a study of the sixth Korea national health and nutrition examination survey (KNHANES 2014-2015). Int $J$ Endocrinol. 2020;2020:7195846. doi:10.1155/2020/7195846

21. Alvarez JA, Ashraf A. Role of vitamin d in insulin secretion and insulin sensitivity for glucose homeostasis. Int $J$ Endocrinol. 2010;2010:351385. doi:10.1155/2010/351385

22. McGill AT, Stewart JM, Lithander FE, et al. Relationships of low serum vitamin D3 with anthropometry and markers of the metabolic syndrome and diabetes in overweight and obesity. Nutr J. 2008;7:4. doi:10.1186/1475-2891-7-4

23. Khader YS, Batieha A, Jaddou $H$, et al. Relationship between 25-hydroxyvitamin D and metabolic syndrome among Jordanian adults. Nutr Res Pract. 2011;5(2):132-9. doi:10.4162/nrp.2011.5.2.132

24. He C, Lin Z, Robb S, et al. Serum Vitamin D levels and polycystic ovary syndrome: a systematic review and meta-analysis. Nutrients. 2015;7(6):4555-4577. doi:10.3390/nu7064555

25. Asemi Z. Calcium plus vitamin D supplementation affects glucose metabolism and lipid concentrations in overweight and obese vitamin D deficient women with polycystic ovary syndrome. Clin Nutr. 2015;34(4):586-592. doi:10.1016/j.clnu.2014.09.015

26. Rajpathak SN, Xue X, Wassertheil-Smoller S, et al. Effect of $5 \mathrm{y}$ of calcium plus vitamin D supplementation on change in circulating lipids: results from the Women's Health Initiative. Am J Clin Nutr. 2010;91(4):894-899. doi:10.3945/ajen.2009.28579

27. Gannagé-Yared MH, Azoury M, Mansour I, et al. Effects of a short-term calcium and vitamin D treatment on serum cytokines, bone markers, insulin and lipid concentrations in healthy post-menopausal women. $J$ Endocrinol Invest. 2003;26(8):748-753. doi:10.1007/BF03347358

28. Querfeld U, Hoffmann MM, Klaus G, et al. Antagonistic effects of vitamin D and parathyroid hormone on lipoprotein lipase in cultured adipocytes. J Am Soc Nephrol. 1999;10(10):2158-2164. doi:10.1681/ ASN.V10102158

29. Hewison M. An update on vitamin D and human immunity. Clin Endocrinol (Oxf). 2012;76(3):315-325. doi:10.1111/j.1365-2265.20 11.04261.x

30. Chagas CE, Borges MC, Martini LA, et al. Focus on vitamin D, inflammation and type 2 diabetes. Nutrients. 2012;4(1):52-67. doi:10.3390/nu4010052

31. Yousefzadeh P, Shapses SA, Wang X. Vitamin D binding protein impact on 25-Hydroxyvitamin D levels under different physiologic and pathologic conditions. Int $J$ Endocrinol. 2014;2014:981581. doi:10.1155/2014/981581

32. Jassil NK, Sharma A, Bikle D, et al. Vitamin d binding protein and 25-hydroxyvitamin D levels: emerging clinical applications. Endocr Pract. 2017;23(5):605-613. doi:10.4158/EP161604.RA 


\section{Publish your work in this journal}

The International Journal of General Medicine is an international, peer-reviewed open-access journal that focuses on general and internal medicine, pathogenesis, epidemiology, diagnosis, monitoring and treatment protocols. The journal is characterized by the rapid reporting of reviews, original research and clinical studies across all disease areas. The manuscript management system is completely online and includes a very quick and fair peer-review system, which is all easy to use. Visit http://www.dovepress.com/ testimonials.php to read real quotes from published authors. 